\title{
Evaluation of Aromatic Thiols as Photoinitiators
}

\author{
Dillon Love, ${ }^{\dagger}$ Benjamin Fairbanks, ${ }^{\prime}$ and Christopher Bowman $*,+, k$,
}

${ }^{\dagger}$ Department of Chemical and Biological Engineering, "Department of Chemistry

and Biochemistry, and ${ }^{\S}$ Materials Science and Engineering Program, University of

Colorado Boulder, Boulder, Colorado 80309, United States 


\section{Section 1. UV/vis spectrums}
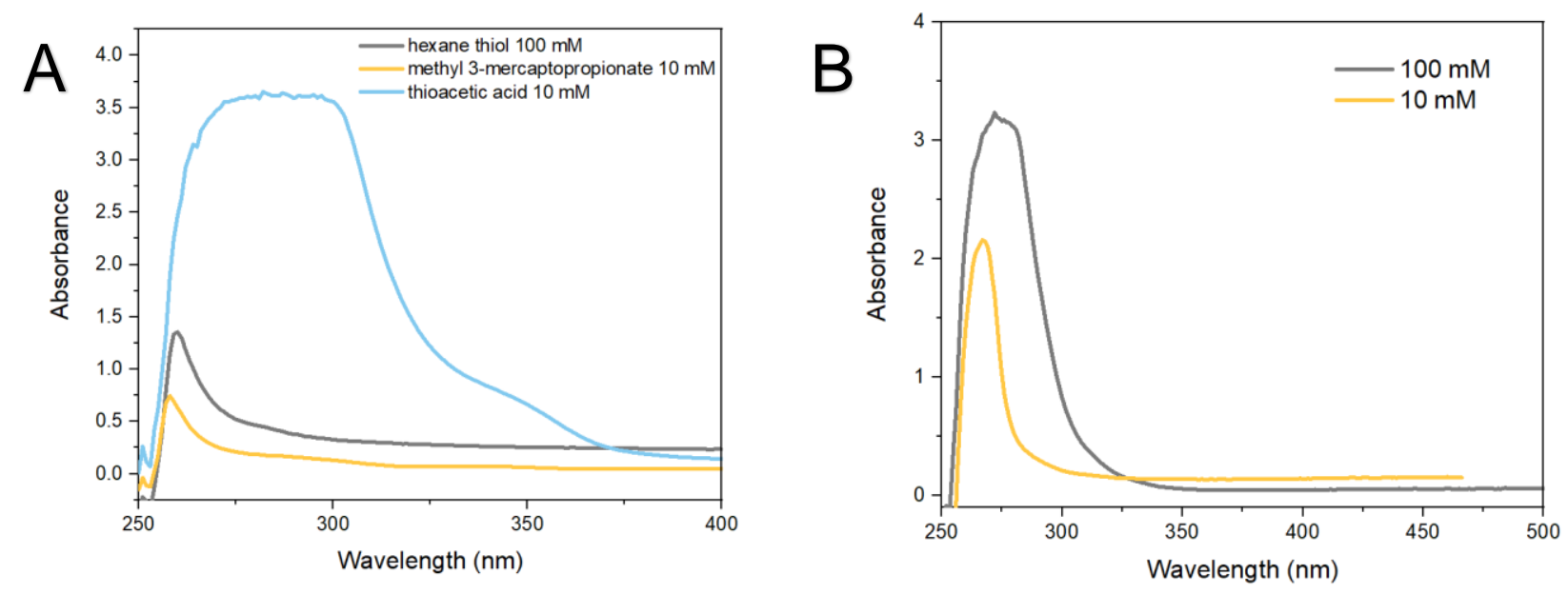

Figure S1. UV/vis spectrums of (A) 1-hexanethiol T1, methyl 3-mercaptopropionate T2, and thioacetic acid T5, (B) benzyl mercaptan T3 in DMSO. 

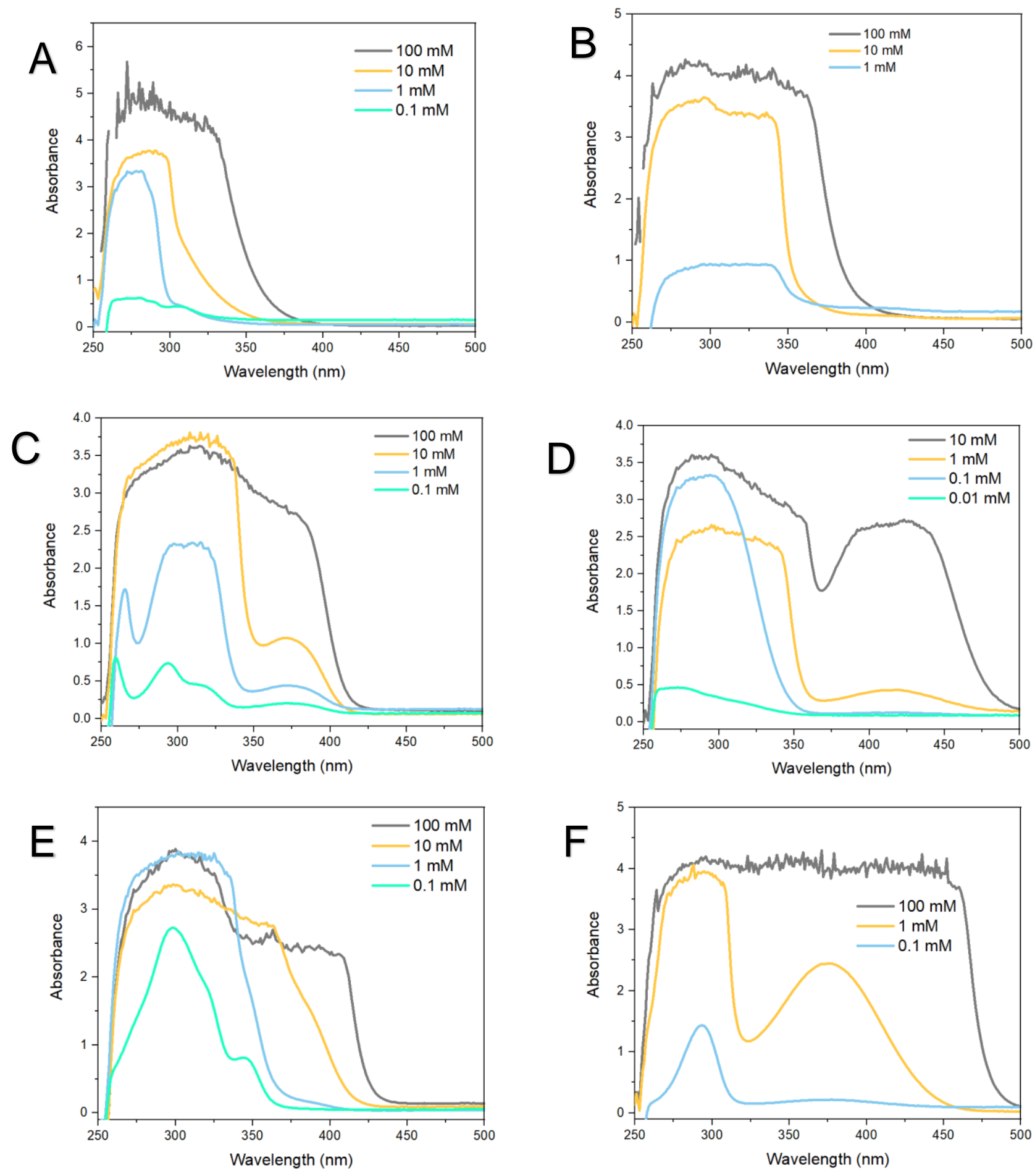

Figure S2. UV/vis spectrum of (A) thiophenol T7, (B) naphthalene thiol T8, (C) thiosalicylic acid T9, (D) thiobenzoic acid T6, (E) trithiocyanuric acid T12, (F) 2-mercaptopyrimidine T11 in DMSO. 

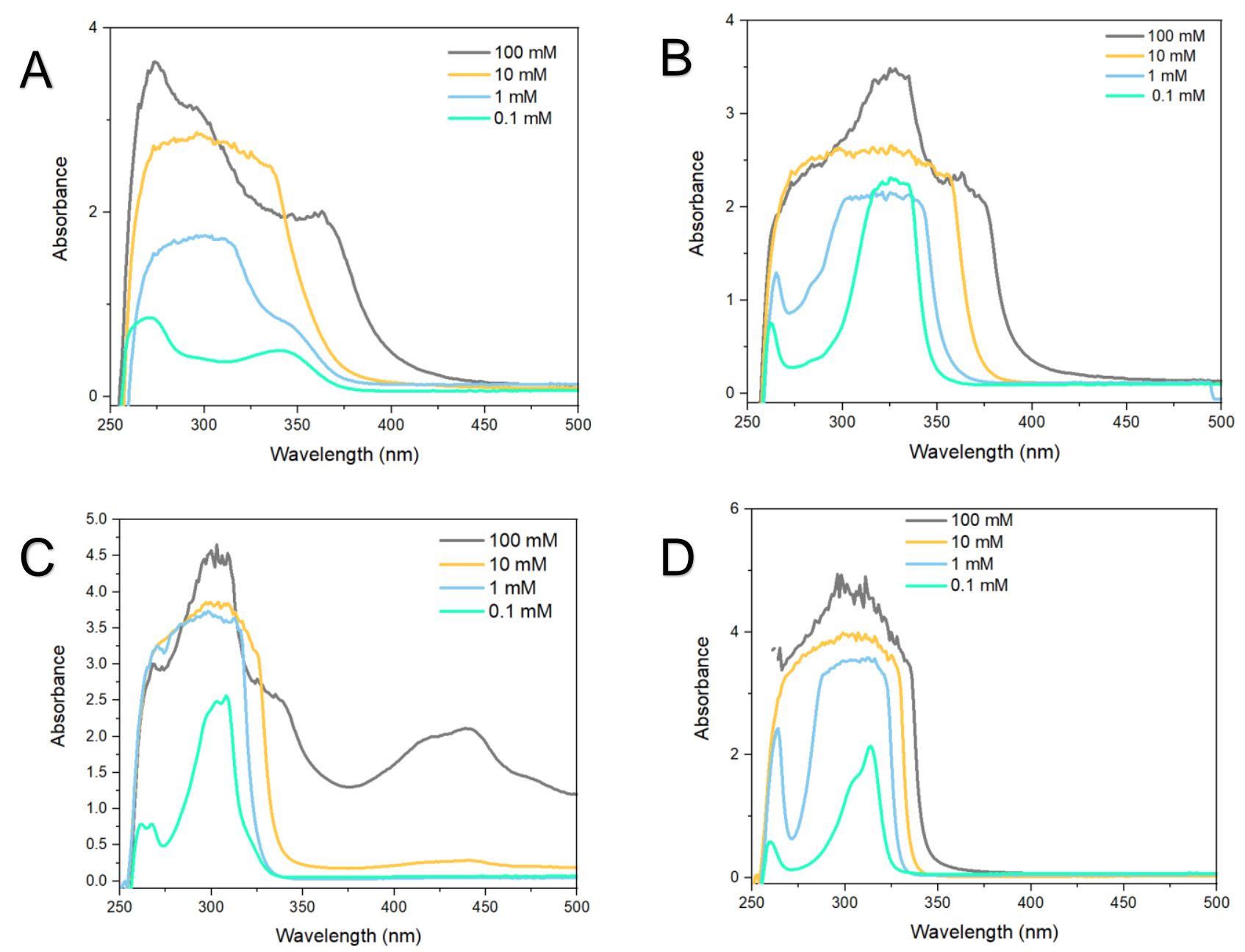

Figure S3. UV/vis spectrum of (A) 4,4'-thiobisbenzenethiol, (B) 2-mercaptobenzothiazole, (C) 2-mercaptobenzooxazole, and (D) 2-mercaptobenzoimidazole in DMSO. 

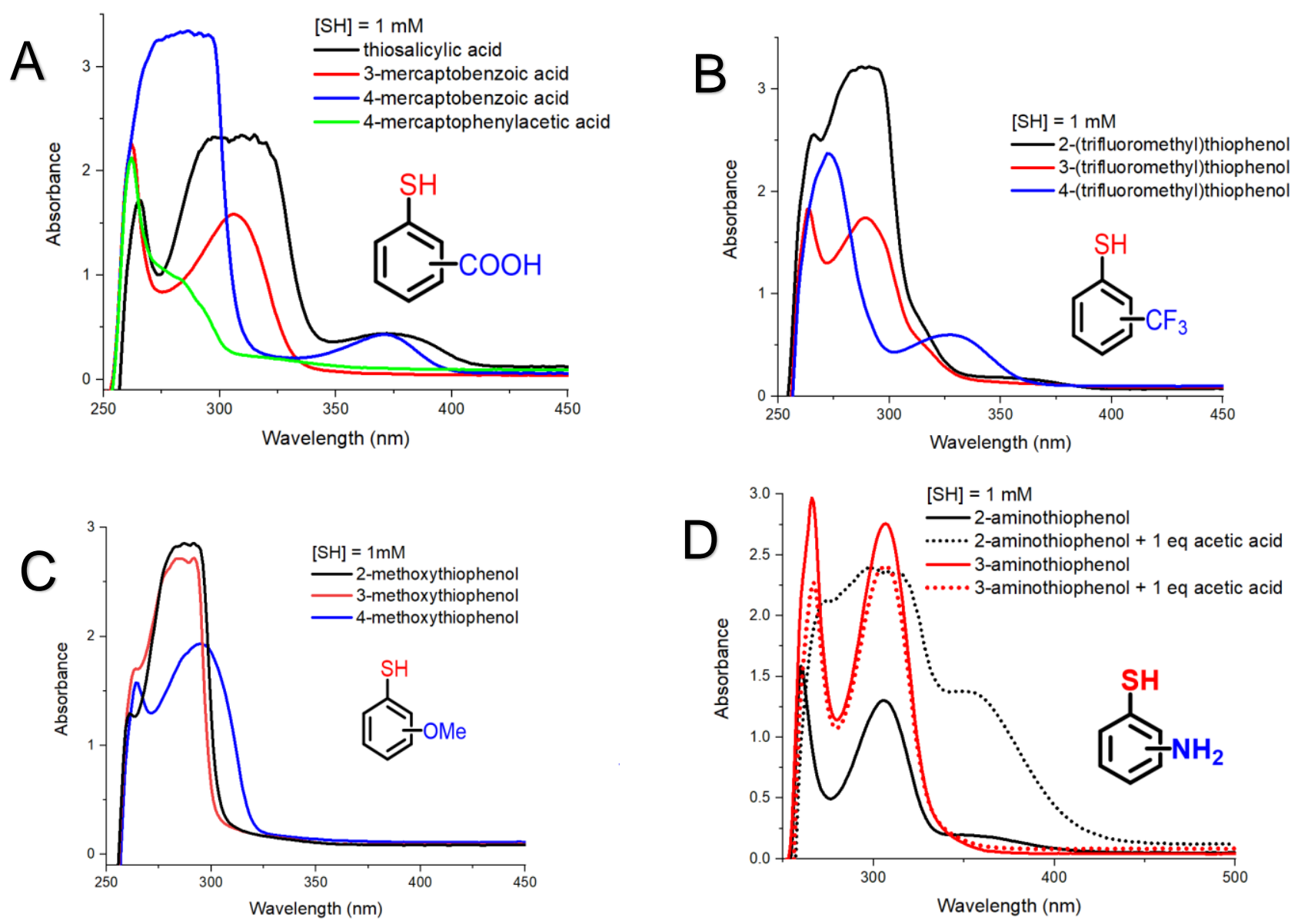

Figure S4. UV/vis spectrum of (trifluoromethyl)thiophenol analogues, aminothiophenol in DMSO.

(A) mercaptobenzoic acid analogues,

(C) methoxythiophenol analogues, and

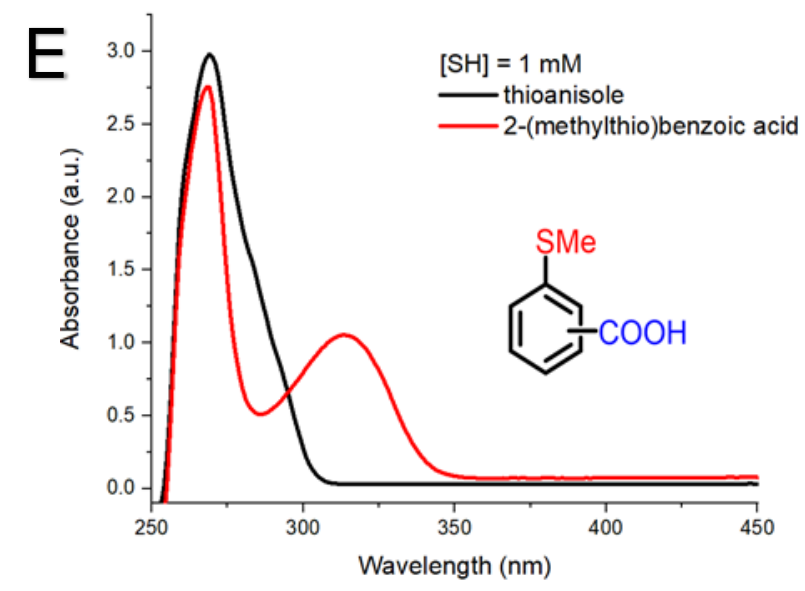

Figure S5: UV/vis spectrum of thioanisole T27 and 2-(methylthio)benzoic acid T28 in DMSO. 

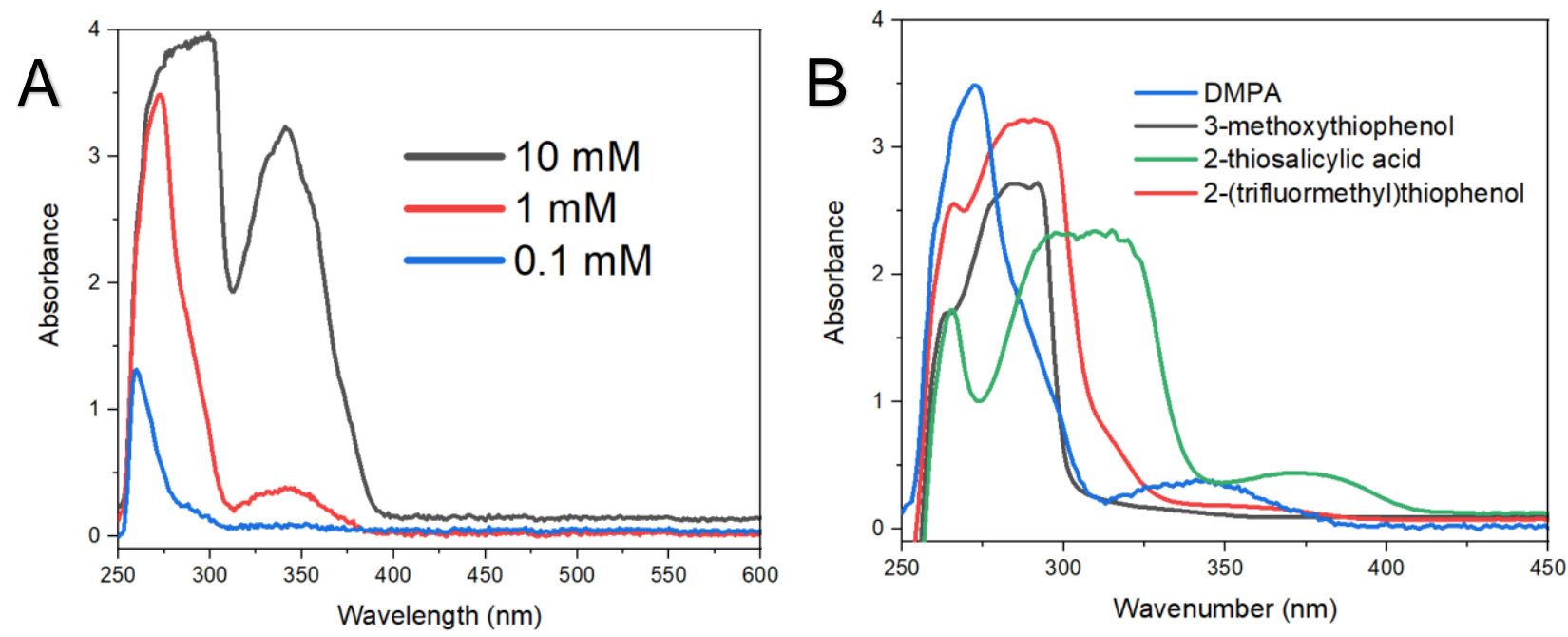

Figure S6. (Left) UV/vis spectrum of 2,2-dimethoxy-2-phenylacetophenone (DMPA) in DMSO at various concentrations. (Right) Comparison of the UV/vis spectrums of DMPA and several substituted thiophenols derivative in DMSO at a concentration of $1 \mathrm{mM}$. 
Table S1: UV/vis absorptivity of thiols in $\mathrm{DMSO}^{a}$

\begin{tabular}{|c|c|c|c|c|c|c|c|}
\hline Thiol & $\begin{array}{l}\text { Concentration } \\
(\mathrm{mM})\end{array}$ & $\begin{array}{c}\lambda \text { of max } \\
\text { absorption } \\
\text { (nm) }\end{array}$ & $\begin{array}{l}\varepsilon 260 \\
\left(\mathrm{~cm}^{2}\right. \\
\left.\mathrm{mol}^{-1}\right)\end{array}$ & $\begin{array}{l}\varepsilon 300 \\
\left(\mathrm{~cm}^{2}\right. \\
\left.\mathrm{mol}^{-1}\right)\end{array}$ & $\begin{array}{l}\varepsilon_{320} \\
\left(\mathrm{~cm}^{2}\right. \\
\left.\mathrm{mol}^{-1}\right)\end{array}$ & $\begin{array}{l}\varepsilon_{365} \\
\left(\mathrm{c}^{2} \mathrm{~mol}^{-}\right. \\
1)\end{array}$ & $\begin{array}{l}\varepsilon 400 \\
\left(\mathrm{~cm}^{2}\right. \\
\left.\mathrm{mol}^{-1}\right)\end{array}$ \\
\hline T1 & 100 & 260 & 11 & 1 & $\mathrm{X}$ & $\mathrm{X}$ & $\mathrm{X}$ \\
\hline T2 & 100 & 263 & 31 & 28 & 3 & $\mathrm{X}$ & $\mathrm{X}$ \\
\hline T3 & 100 & 267 & 32 & 22 & 8 & 2 & $\mathrm{X}$ \\
\hline T4 & 100 & $\mathrm{X}$ & $\mathrm{X}$ & $\mathrm{X}$ & $\mathrm{X}$ & $\mathrm{X}$ & $\mathrm{X}$ \\
\hline T5 & 1 & 272 & 1,400 & 53 & 26 & 45 & $\mathrm{X}$ \\
\hline T6 & 0.1 & 294 & 19,000 & 32,000 & 21,000 & 270 & 340 \\
\hline T7 & 1 & 278 & 3,300 & 2,300 & 530 & 206 & $\mathrm{X}$ \\
\hline T8 & 1 & 324 & 0 & 780 & 760 & 140 & 63 \\
\hline T9 & 1 & 315 & 920 & 2,200 & 2,100 & 310 & 110 \\
\hline T10 & 1 & 296 & 0 & 1,607 & 1,300 & 200 & 0 \\
\hline T11 & 1 & 288 & 1,600 & 3,900 & 1,200 & 2,300 & 1,900 \\
\hline T12 & 1 & 302 & 1,900 & 3,800 & 3,700 & 370 & 57 \\
\hline T13 & 1 & 321 & 450 & 2,000 & 2,100 & 190 & 110 \\
\hline T14 & 1 & 296 & 2,000 & 3,700 & 1,800 & 0 & 0 \\
\hline T15 & 1 & 312 & 1,700 & 3,500 & 3,300 & 0 & 0 \\
\hline T16 & 1 & 262 & 2,000 & 1,400 & 930 & 0 & 0 \\
\hline T17 & 1 & 283 & 2,000 & 2,600 & 180 & 350 & 31 \\
\hline T18 & 1 & 262 & 1,800 & 280 & 120 & 18 & 0 \\
\hline T19 & 1 & 292 & 1,200 & 1,200 & 97 & 0 & 0 \\
\hline T20 & 1 & 292 & 1,200 & 530 & 93 & 0 & 0 \\
\hline T21 & 1 & 295 & 1,100 & 1,700 & 180 & 0 & 0 \\
\hline T22 & 1 & 288 & 1,800 & 2,500 & 430 & 86 & 0 \\
\hline T23 & 1 & 289 & 1,300 & 1,300 & 310 & 28 & 0 \\
\hline T24 & 1 & 272 & 1,200 & 400 & 540 & 95 & 62 \\
\hline T25 & 1 & 305 & 1,500 & 1,200 & 720 & 130 & 30 \\
\hline T25 $(\mathrm{H})^{+b}$ & 1 & 299 & 850 & 2,200 & 2,100 & 1,100 & 320 \\
\hline T26 & 1 & 307 & 2,100 & 2,500 & 1,500 & 590 & 0 \\
\hline T26 $(\mathrm{H})^{+}$ & 1 & 307 & 1,300 & 2,200 & 1,400 & 880 & 0 \\
\hline T27 & 1 & 268 & 2,000 & 230 & 0 & 0 & 0 \\
\hline T28 & 1 & 271 & 1,700 & 720 & 900 & 0 & 0 \\
\hline
\end{tabular}

${ }^{a} \mathrm{UV} / \mathrm{vis}$ absorption spectrums were recorded at concentrations between $100 \mathrm{mM}$ and $0.1 \mathrm{mM}$, and molar attenuation coefficients $\varepsilon$ were calculated according to Beer's Law, $A=\varepsilon c l$; where $A$ is absorbance, $c$ is concentration, and $l$ is the path length $(1 \mathrm{~cm}) .{ }^{b}$ Amino thiophenol derivatives, T25 and T26, were protonated with 1 equivalent of acetic acid to afford the protonated $\mathbf{T} 25(\mathrm{H})^{+}$ and $\mathbf{T 2 6}(\mathrm{H})^{+}$species. Neutral acetic acid in DMSO has no absorbance in the wavelengths observed. 


\section{Section 2. Acrylate Photoinitiation}

Table S2: Rates of acrylate photopolymerization with thiols as photointitators initiated with 320$390 \mathrm{~nm} \operatorname{light}^{a}$

\begin{tabular}{|c|c|c|c|}
\hline Thiol & $\begin{array}{c}{[\mathrm{SH}]} \\
(\mathrm{mM})\end{array}$ & $\begin{array}{c}\text { Rate of acrylate } \\
\text { conversion }\left(\mathrm{M} \mathrm{min}^{-1}\right)^{b}\end{array}$ & $\begin{array}{c}\text { Acrylate conversion after 15 } \\
\text { min of irradiation }(\%)^{c}\end{array}$ \\
\hline T1 & 300 & ---- & $55 \pm 6$ \\
\hline T2 & 300 & --- & $50 \pm 4$ \\
\hline T3 & 300 & ---- & $66 \pm 4$ \\
\hline T4 & 30 & ---- & $31 \pm 2$ \\
\hline T5 & 30 & 0.23 & $90 \pm 3$ \\
\hline T6 & 30 & 2.1 & 100 \\
\hline T7 & 30 & 3.1 & 100 \\
\hline T8 & 30 & 3.2 & 100 \\
\hline T9 & 30 & 3.6 & 100 \\
\hline T10 & $60 d$ & 4.2 & 100 \\
\hline T11 & 30 & 0.98 & $90 \pm 2$ \\
\hline T12 & 30 & 0.94 & $89 \pm 3$ \\
\hline T13 & 30 & ---- & $74 \pm 3$ \\
\hline T14 & 30 & --- & $49 \pm 6$ \\
\hline T15 & 30 & ---- & $32 \pm 5$ \\
\hline
\end{tabular}

${ }^{a}$ Reactions were formulated with HA (3 M in DMSO) and thiol initiator at varying concentrations. Reactions were initiated with 320-390 nm light with intensities of $10.0,8.5$, and $31 \mathrm{~mW} \mathrm{~cm}^{-2}$ at $320 \mathrm{~nm}, 365 \mathrm{~nm}$, and over all wavelengths combined, respectively. ${ }^{b}$ Rates were calculated only for reactions that achieved $\sim 90 \%$ acrylate conversion. ${ }^{c}$ Conversions measured by ${ }^{1} \mathrm{H}$ NMR. ${ }^{d} \mathbf{T 1 0}$ is difunctional. 

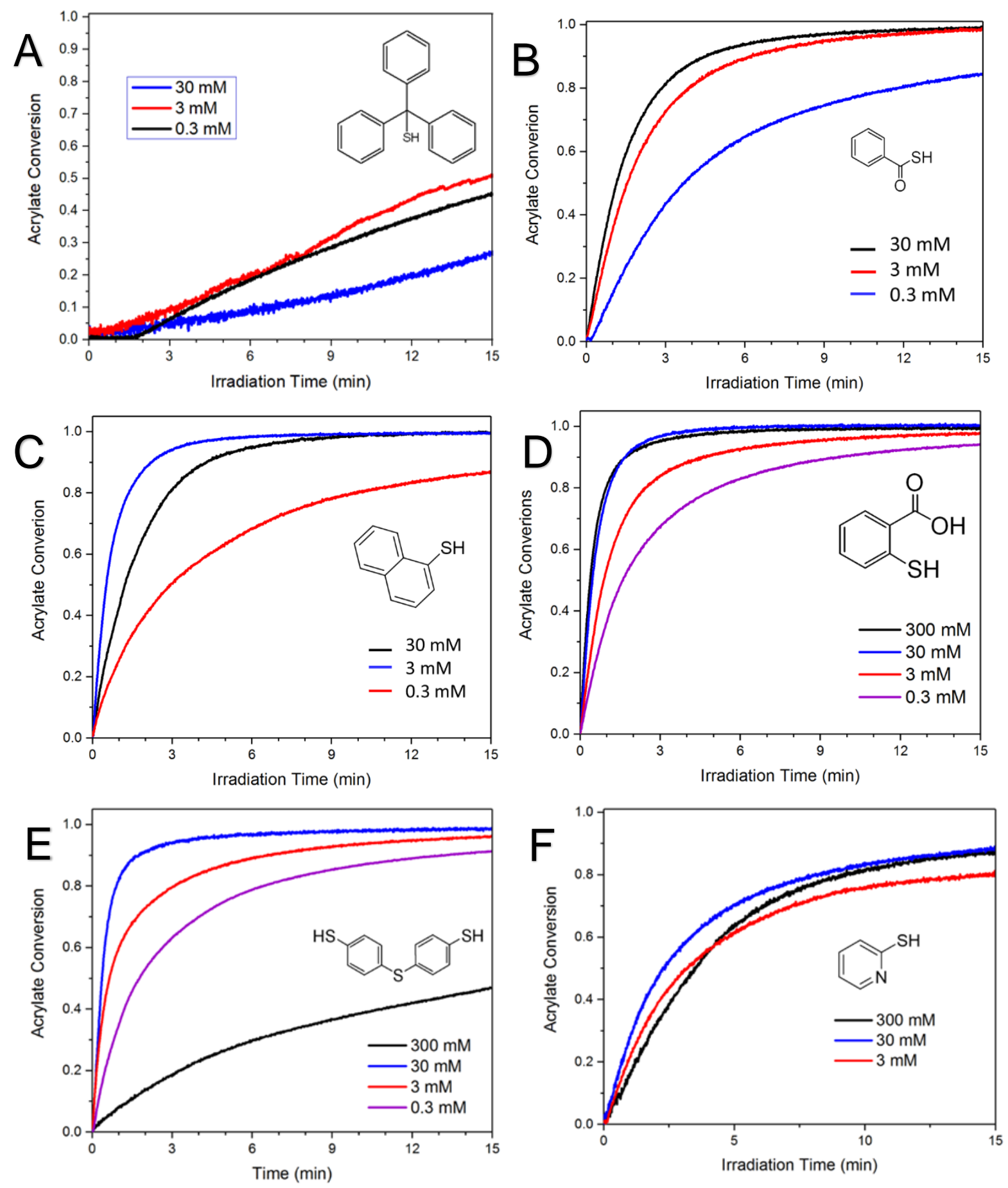

Figure S7: Acrylate conversion profile as a function of irradiation time for the photopolymerization of HA (3 M in DMSO) with (A) T4, (B) T6, (C) T8, (D) T9, (E) T10, and (F) T11 as the photoinitiator. Reactions were irradiated with $320-390 \mathrm{~nm}$ light with intensities of $10.0,8.5$, and $31 \mathrm{~mW} \mathrm{~cm}^{-2}$ at $320 \mathrm{~nm}, 365 \mathrm{~nm}$, and over all wavelengths combined, respectively. 


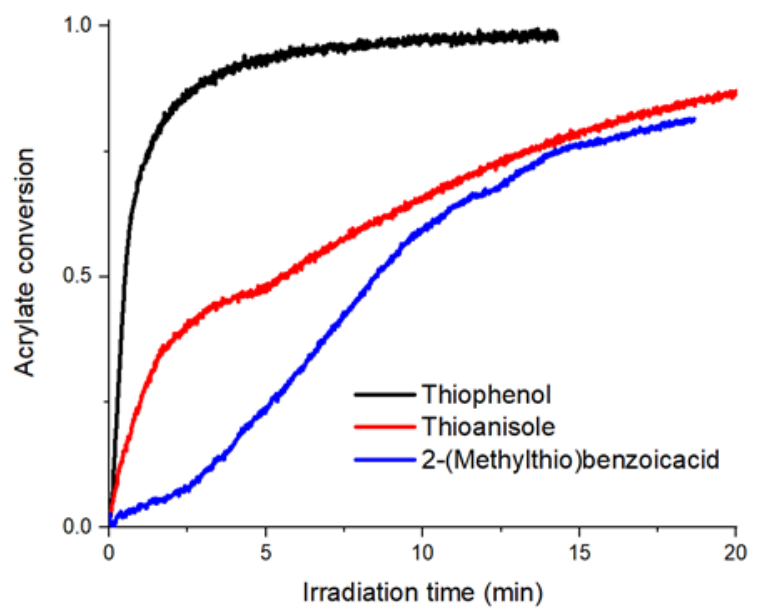

Figure S8: Acrylate conversion profile as a function of irradiation time for the photopolymerization of HA (3 M in DMSO) with thiophenol T7, thioanisole T27, and 2(methylthio)benzoic acid T28 as the photoinitiator $(30 \mathrm{mM})$. Reactions were irradiated with 320$390 \mathrm{~nm}$ light with intensities of $10.0,8.5$, and $31 \mathrm{~mW} \mathrm{~cm}{ }^{-2}$ at $320 \mathrm{~nm}, 365 \mathrm{~nm}$, and over all wavelengths combined, respectively.

S10 

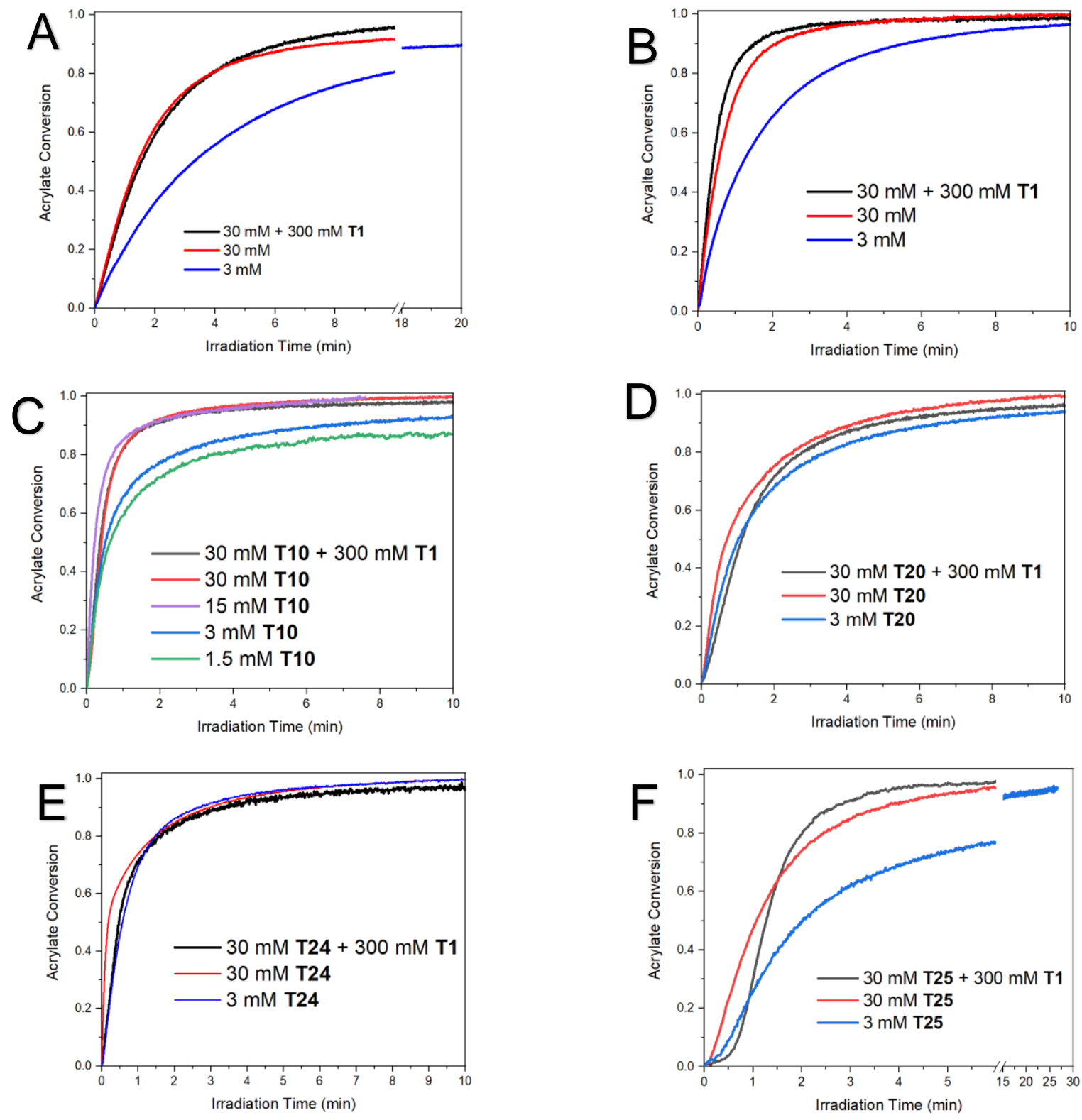

Figure S9: Comparison of acrylate conversion profiles as a function of irradiation time for the photopolymerization of HA (3 M in DMSO) with (A) T6, (B) T9, (C) T10, (D) T20, (E) T24, and (F) $\mathbf{T 2 5}$ as the photoinitiator and with or without T1 present as a CT agent. Reactions were irradiated with $320-390 \mathrm{~nm}$ light with intensities of $10.0,8.5$, and $31 \mathrm{~mW} \mathrm{~cm}^{-2}$ at $320 \mathrm{~nm}, 365 \mathrm{~nm}$, and over all wavelengths combined, respectively. 

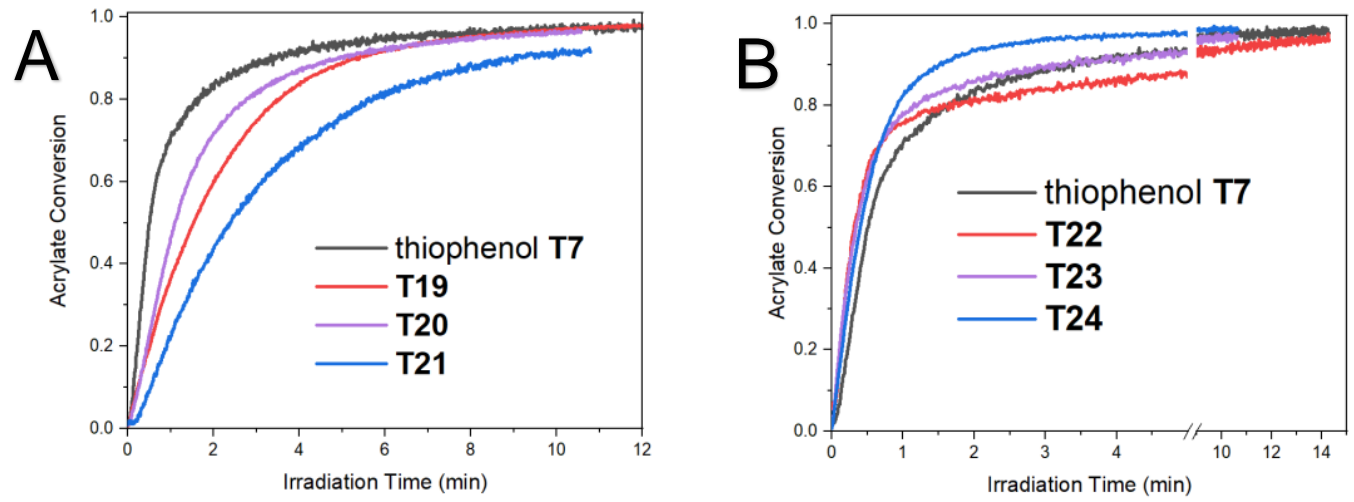

Figure S10. Comparison of acrylate conversion profiles as a function of irradiation time for the photopolymerization of HA (3M in DMSO) with (A) T7, T19, T20, and T21 (B) T7, T22, T23, and $\mathbf{T} 24$ as the photoinitiator $(30 \mathrm{mM})$

Table S3: Rates of acrylate photopolymerization with thiols as photointitators

\begin{tabular}{|c|c|c|c|c|c|c|}
\hline & \multicolumn{2}{|c|}{$\begin{array}{c}c=3 \mathrm{mM}, \lambda=320-390 \mathrm{~nm} \mathrm{(31} \\
\left.\mathrm{mW} \mathrm{cm}^{-2}\right)\end{array}$} & \multicolumn{2}{|c|}{$\begin{array}{c}c=30 \mathrm{mM}, \lambda=365 \mathrm{~nm}(10 \\
\left.\mathrm{mW} \mathrm{cm}{ }^{-2}\right)\end{array}$} & \multicolumn{2}{|c|}{ 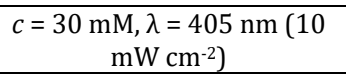 } \\
\hline Thiol & 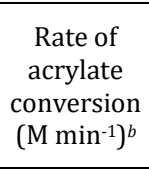 & $\begin{array}{c}\text { Acrylate } \\
\text { conversion } \\
\text { after } 15 \text { min of } \\
\text { irradiation } \\
(\%)^{c}\end{array}$ & $\begin{array}{c}\text { Rate of } \\
\text { acrylate } \\
\text { conversion } \\
\left(\mathrm{M} \mathrm{min}^{-1}\right)^{b}\end{array}$ & $\begin{array}{l}\text { Acrylate } \\
\text { conversion } \\
\text { after } 15 \text { min of } \\
\text { irradiation } \\
(\%)^{c}\end{array}$ & $\begin{array}{c}\text { Rate of } \\
\text { acrylate } \\
\text { conversion } \\
\left(\mathrm{M} \mathrm{min}^{-1}\right)^{b}\end{array}$ & $\begin{array}{c}\text { Acrylate } \\
\text { conversion } \\
\text { after } 15 \text { min } \\
\text { of irradiation } \\
(\%)^{c}\end{array}$ \\
\hline T3 & --- & --- & 0.14 & $75 \pm 5$ & --- & $12 \pm 8$ \\
\hline T6 & 0.42 & $92 \pm 2$ & 0.16 & $88 \pm 4$ & ---- & ---- \\
\hline T7 & 1.2 & 100 & 0.45 & $95 \pm 2$ & 0.35 & $92 \pm 3$ \\
\hline T9 & 1.1 & 100 & 0.85 & 100 & 0.89 & 100 \\
\hline T10 & 3.0 & $93 \pm 4$ & 0.53 & $96 \pm 1$ & 0.93 & $95 \pm 3$ \\
\hline T17 & 5.5 & 100 & 2.8 & 100 & 2.3 & 100 \\
\hline T20 & 1.4 & 100 & 0.48 & 100 & 0.22 & $87 \pm 6$ \\
\hline T22 & 1.4 & 100 & 1.8 & 100 & 1.00 & 100 \\
\hline T23 & 2.6 & $97 \pm 1$ & 0.74 & $97 \pm 1$ & 0.21 & $88 \pm 3$ \\
\hline T24 & 1.4 & 100 & 0.95 & 100 & 0.89 & $94 \pm 3$ \\
\hline T25 & 0.82 & $96 \pm 2$ & 0.56 & 100 & 1.8 & 100 \\
\hline T25(H)+ & 0.16 & $65 \pm 3$ & 0.30 & $99 \pm 1$ & --- & $65 \pm 7$ \\
\hline
\end{tabular}

${ }^{a}$ Reactions were formulated with HA (3 M in DMSO) and thiol initiator at varying concentrations. ${ }^{b}$ Rates were calculated only for reactions that achieved $100 \%$ acrylate conversion. ${ }^{c}$ Conversions measured by ${ }^{1} \mathrm{H}$ NMR. 


\section{Section 3. Additional Figures}

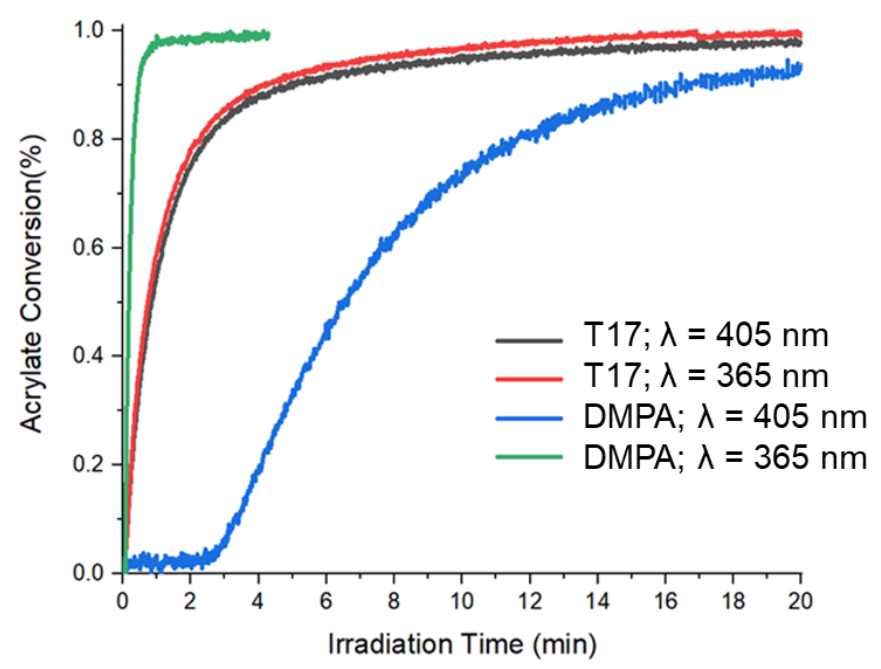

Figure S11. Acrylate conversion profiles as a function of irradiation time for the HA (3 M in DMSO) polymerization initiated by DMPA or T17 (1 wt \%). Reactions were irradiated with 365 $\mathrm{nm}$ or $405 \mathrm{~nm}$ light at an intensity of $10 \mathrm{~mW} \mathrm{~cm}^{-2}$.

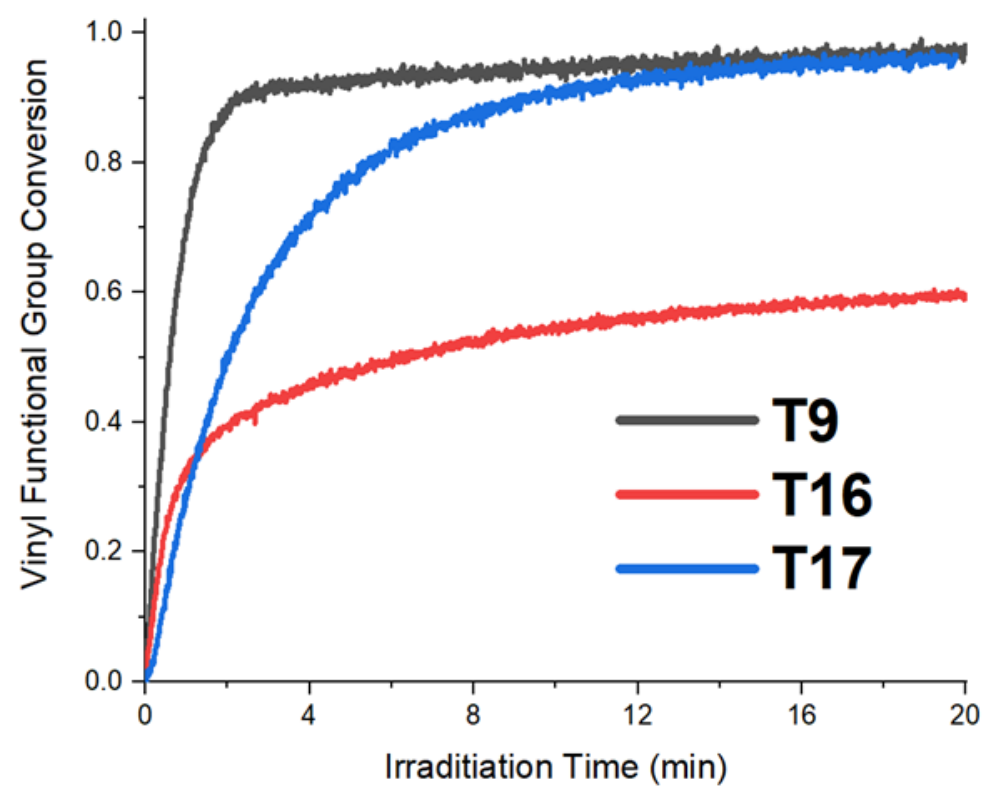

Figure S12: Vinyl ether conversion profiles for the solventless photopolymerization of PETM with 1,4-butanediol divinyl ether $[\mathrm{SH}]=$ [ene] using mercaptobenzoic acid derivatives as PIs in TEC network polymerizations. Reactions were irradiated with $405 \mathrm{~nm}$ light at an intensity of 10 $\mathrm{mW} \mathrm{cm}{ }^{-2}$. 


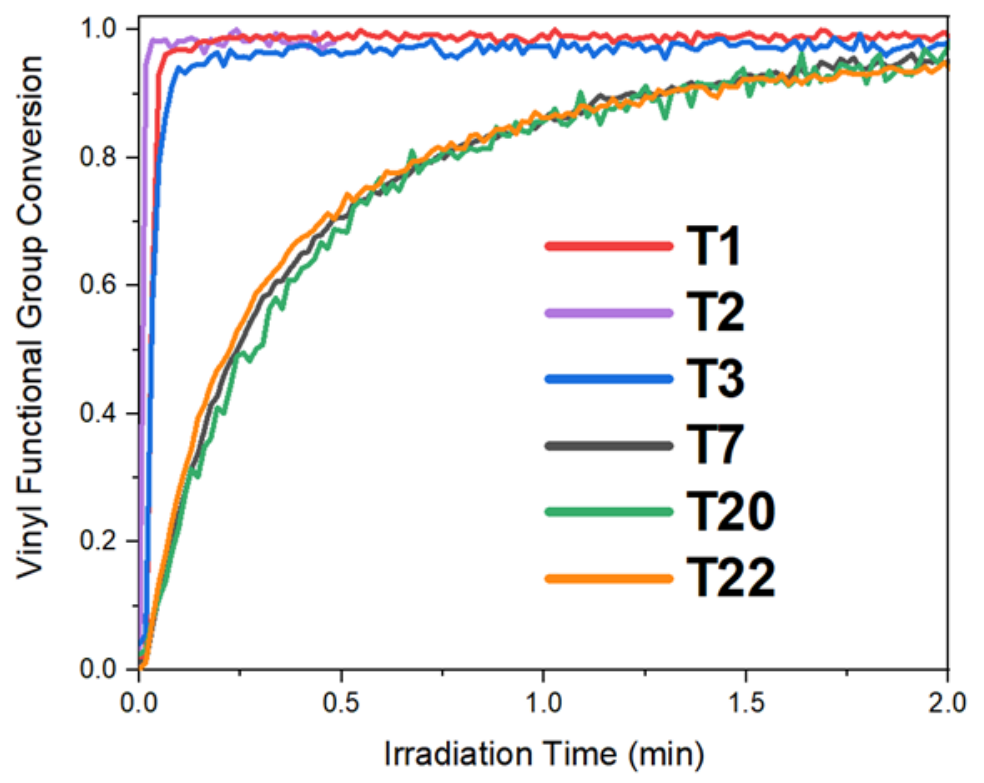

Figure S13: Comparison of vinyl functional group conversion profiles as a function of irradiation time for the solventless reaction between thiols T1-3, T7, T20, and T22. Reactions were formulated with $1 \mathrm{wt} \%$ DMPA as a photoinitiator and were irradiated with $365 \mathrm{~nm}$ light at an intensity of $10 \mathrm{~mW} \mathrm{~cm} \mathrm{~cm}^{-2}$. 


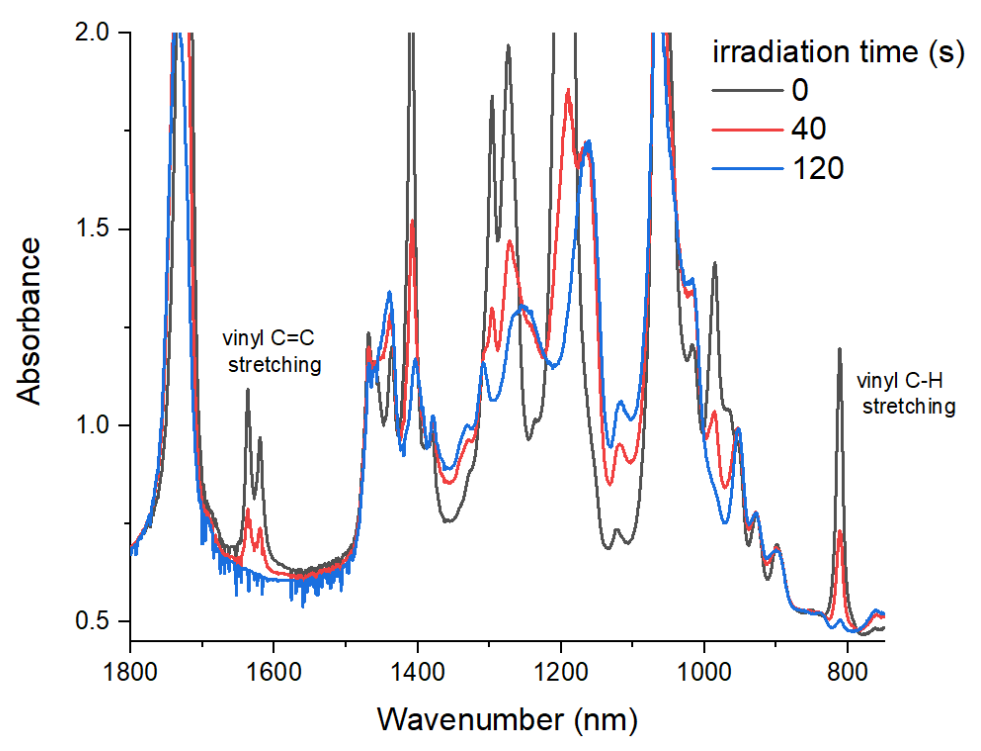

Figure S14: FTIR absorbance spectra of the polymerization of n-hexyl acrylate (3M in DMSO) using 1 mol\% 2-mercaptobenzoic acid (T9) as the photoinitiator. The reaction was irradiated with $365 \mathrm{~nm}$ light $\left(10 \mathrm{~mW} \mathrm{~cm}^{-2}\right)$ and spectra correspond to 0,40 , and $120 \mathrm{~s}$ of irradiation. 


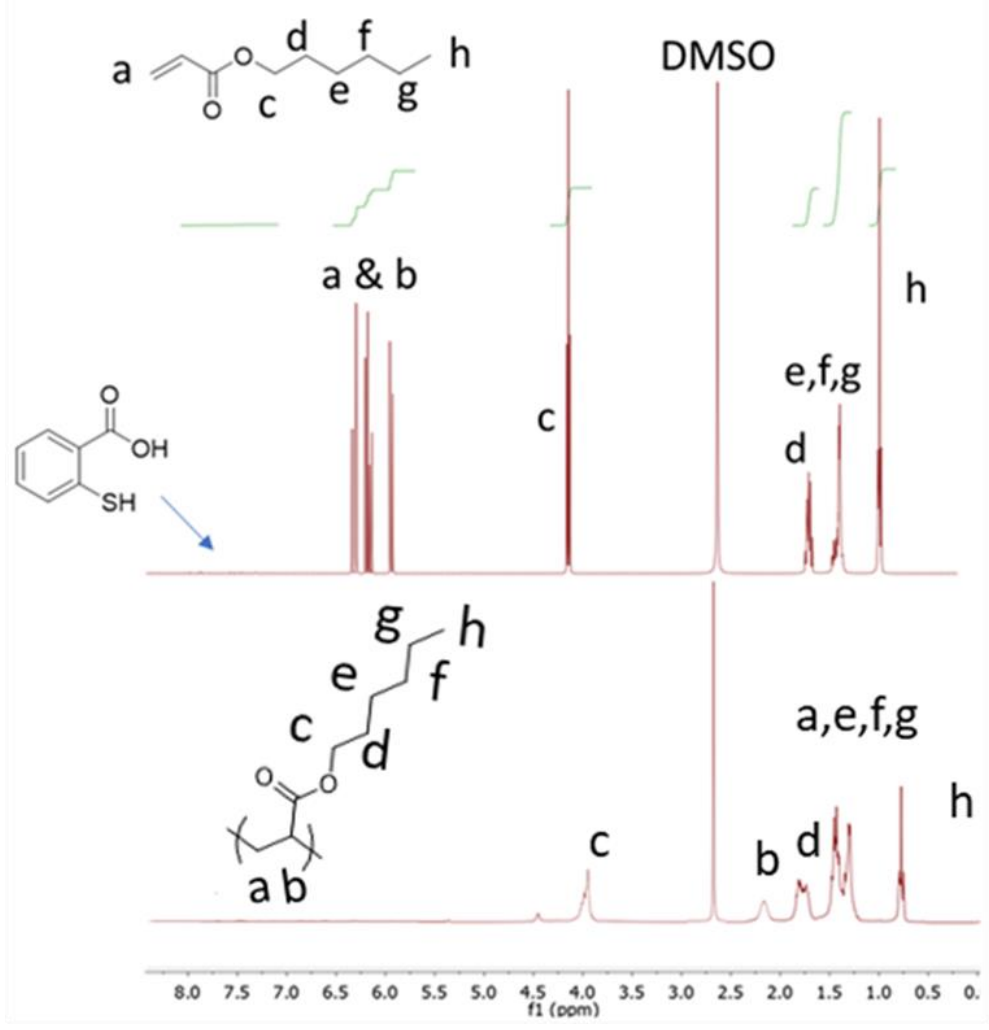

Figure S15: $\mathrm{H}^{1}$ NMR spectra of the polymerization of $\mathrm{n}$-hexyl acrylate (3M in DMSO) using 1 mol\% 2-mercaptobenzoic acid (T9) as the photoinitiator. The reaction was irradiated with 365 $\mathrm{nm}$ light $\left(10 \mathrm{~mW} \mathrm{~cm}^{-2}\right)$ for 10 minutes. 

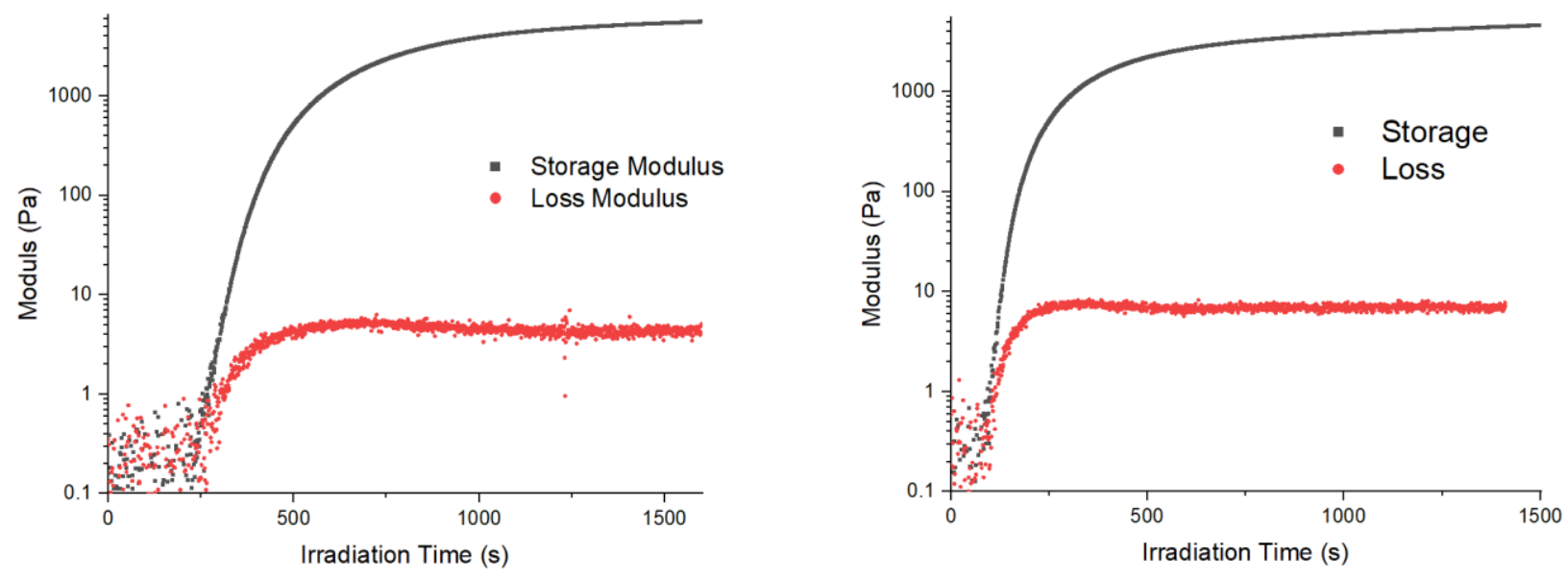

Figure S16: Real time rheological properties as a function of irradiation time for the TEC hydrogel polymerization between PEG2MB and PEG2MP with PEG4NB. Polymerizations were formulated with 10 wt.\% PEG macromer $[\mathrm{SH}]=[$ Ene] in an aqueous solution of sodium phosphate monobasic $\mathrm{pH}$ 4.4. (A) [PEG2MB]:[PEG2MP] $=1: 9 ; \lambda=365 \mathrm{~nm}$. (B) $[\mathrm{PEG} 2 \mathrm{MB}]:[\mathrm{PEG} 2 \mathrm{MP}]=1: 1 ; \lambda=320-$ $390 \mathrm{~nm}$. 


\section{Section 4. Thiolated PEG synthesis and NMRs}

Synthesis of poly(ethylene glycol)-bis(3-mercaptopropionate) (PEG2MP) and poly(ethylene glycol)bis(2-mercaptobenzoic acid) (PEG2MBA). To a flame dried $500 \mathrm{~mL}$ round bottom flask, poly(ethylene glycol) $\mathrm{M}_{\mathrm{n}}=4,600 \mathrm{~g} / \mathrm{mol}(5.0 \mathrm{~g}, 1.09 \mathrm{mmol})$ was dissolved in $150 \mathrm{~mL}$ of toluene at $90{ }^{\circ} \mathrm{C}$. Sodium sulfate anhydrous $(5.0 \mathrm{~g})$ and $20 \mathrm{mmol}$ of 3-mercaptopropionic acid or $60 \mathrm{mmol}$ of 2-mercaptobenzoic acid were added to the reaction mixture. The reaction was stirred overnight at $90{ }^{\circ} \mathrm{C}$ and then was precipitated into $500 \mathrm{~mL}$ of ice-cold diethyl ether. The precipitate was isolated by filtration and then dissolved into $300 \mathrm{~mL}$ of deionized water. The aqueous phase was washed with ethyl acetate $(2 \times 100 \mathrm{~mL})$ and then product was extracted into DCM (3 x $100 \mathrm{~mL}$ ). The DCM phase was then washed with water and then dried with sodium sulfate. The DCM was then removed under vacuum to afford the thiol functionalized product as a free flowing white powder. PEG2MP. Yield (4.2 g, 81\%). ${ }^{1} \mathrm{H}$ NMR $\left(400 \mathrm{MHz}, \mathrm{CDCl}_{3}\right) 3.65$ (m, O-CH $\mathbf{C}_{2}-\mathrm{CH}_{2}-$ O), 2.82-2.75 (m, 4H), 2.70 (td, 4H). PEG2MB. Yield (4.5 g, 84\%). ${ }^{1} \mathrm{H}$ NMR (400 MHz, $\left.\mathrm{CDCl}_{3}\right) 3.66$ (m, $\left.\mathrm{O}-\mathrm{CH}_{2}-\mathrm{CH}_{2}-\mathrm{O}\right), 7.49-7.13(\mathrm{~m}, 4 \mathrm{H})$.

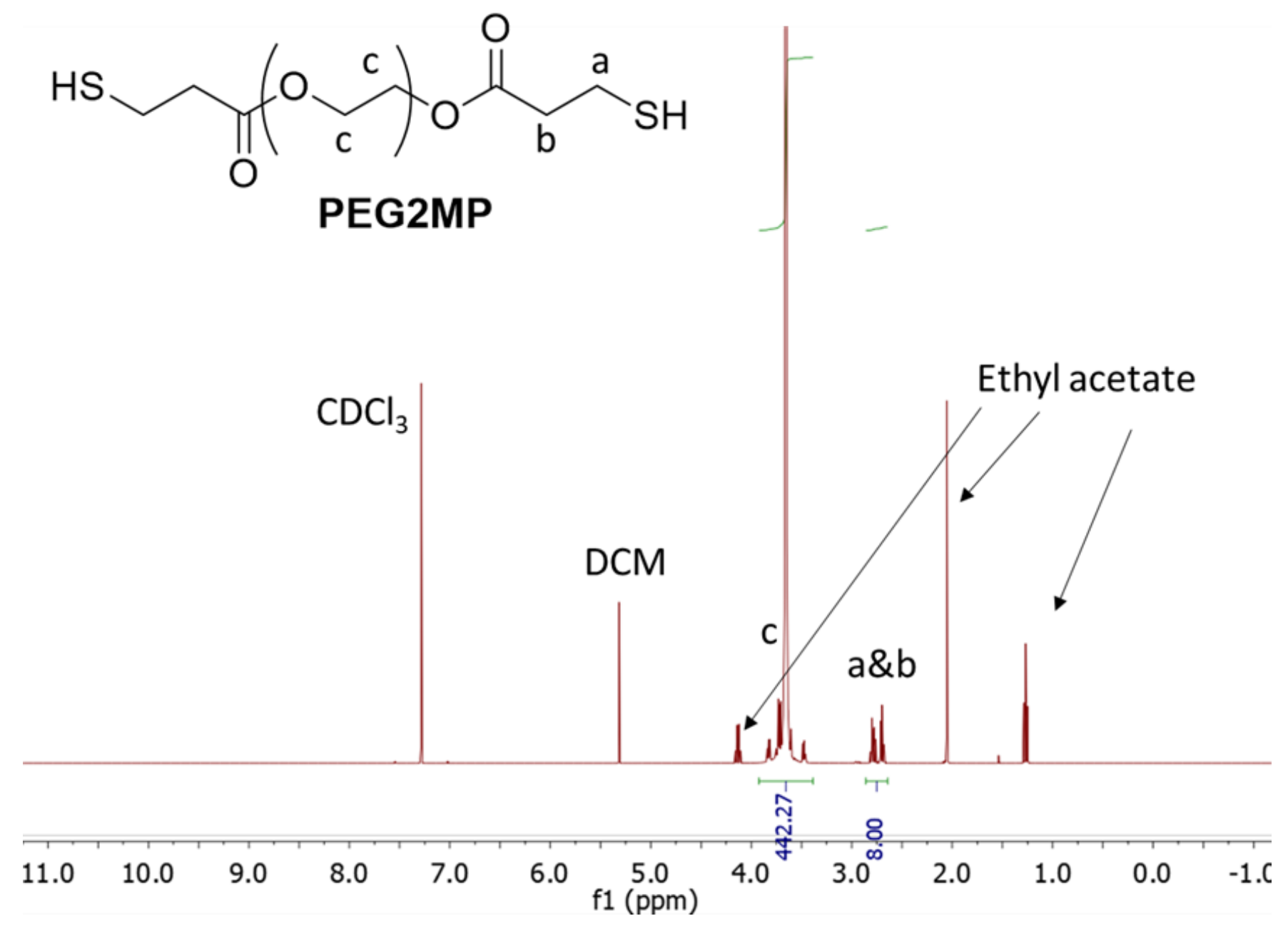

Figure S17. ${ }^{1} \mathrm{H}$ NMR spectrum of PEG2MP. 


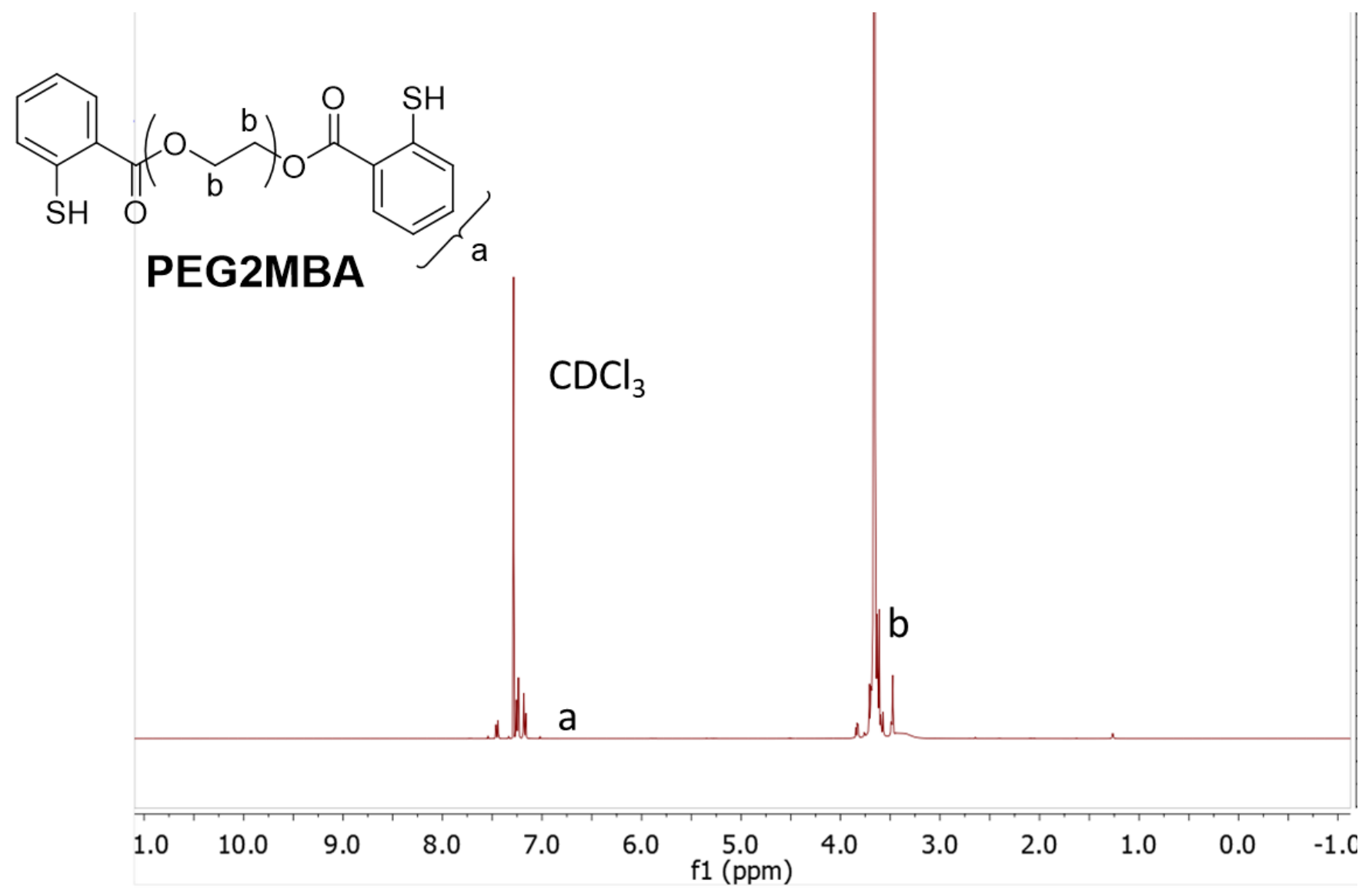

Figure S18. ${ }^{1} \mathrm{H}$ NMR spectrum of PEG2MB. 